\title{
EDUCAÇÃO AMBIENTAL COMO FATOR ESTRUTURANTE DA POLÍTICA NACIONAL DE RESÍDUOS SÓLIDOS: UM ESTUDO A PARTIR DE EXPERIÊNCIAS PRÁTICAS
}

\author{
Carlos Henrique Pereira Leite ${ }^{1}$ \\ José Machado Moita Neto² \\ Ana Keuly Luz Bezerra ${ }^{3}$
}

Resumo: O estudo tem como finalidade evidenciar como a Educação Ambiental pode atuar na consolidação da Política Nacional de Resíduos Sólidos, apresentando, de forma sistêmica os aspectos que circundam a matéria (sociais, ambientais, econômicos) de forma adequada. Para tanto, procedeu-se à análise de três artigos, na qual buscou-se traçar criticamente a rede sistêmica entre os temas abordados, mormente no que diz respeito à relação com a Educação Ambiental. Verificou-se, ao final, a imprescindibilidade da Educação Ambiental como fator estruturante e unificador das mais diversas políticas ambientais, inclusive para a temática relativa à destinação dos resíduos sólidos e, consequentemente, ao desenvolvimento sustentável.

Palavras-chave: Resíduos Sólidos; Visão Sistêmica; Educação Ambiental; Desenvolvimento Sustentável.

Abstract: This study aims to show how Environmental Education can act in the consolidation of the National Solid Waste Policy, presenting, in a systemic way, the aspects that surround the issue (social, environmental, economic) appropriately. To this end, three articles that had Environmental Education as a common object were analyzed. In the end, it was found that environmental education is essential as a structuring and unifying factor for the diverse environmental policies, including for the matter related to the destination of solid waste and, consequently, to sustainable development.

Keywords: Solid Waste; Systemic View; Environmental Education; Sustainable Development.

\footnotetext{
1 Universidade Federal do Piauí (UFPI). E-mail: carlospleite@hotmail.com Link para o Lattes: http://lattes.cnpq.br/2444040512522632

2 Universidade Federal do Piauí (UFPI).E-mail: jose.machado.moita.neto@gmail.com Link para o Lattes: http://lattes.cnpq.br/5047924139977100

3 Universidade Federal do Piauí (UFPI). E-mail: analuz@ifpi.edu.br Link para o Lattes: http://lattes.cnpq.br/9779727227180112
} 


\section{Introdução}

O aumento gradativo dos resíduos gerados, fruto do atual modelo de consumo de massa, somado à histórica falta de investimento e de políticas públicas na seara ambiental, revela o conflito entre a necessidade do desenvolvimento econômico e a falta de planejamento para o controle das consequências inerentes. Referida conjuntura é agravada pelo descumprimento, por parte das municipalidades, das metas e objetivos do Plano Nacional de Resíduos Sólidos (PNRS), previsto na Lei nº 12.305/2010 (BRASIL, 2010).

Os municípios brasileiros, além das características socioeconômicas relativas a uma nação em desenvolvimento, enfrentam problemas ambientais de igual gravidade, especialmente a ausência homogênea de uma prévia coleta seletiva na grande parte das cidades, bem como a inadequação no destino dos resíduos sólidos gerados em seus territórios. Basta-se observar os lixões a céu aberto que subsistem em boa parte das cidades mais economicamente frágeis, com a desobediência dos prazos legais previstos para a desativação, embora sucessivamente prorrogados.

Por sua vez, a questão ambiental ocupa importância cada vez maior no cenário político mundial, com a assunção crescente de obrigações pelos componentes da comunidade internacional. A Conferência de Estocolmo, em 1972, é considerada o marco das discussões públicas internacionais sobre a questão ambiental (THOMÉ, 2015). Desde o referido evento, passando atualmente pela Agenda 2030 da Organização das Nações Unidas (ONU) e pelos Objetivos de Desenvolvimento Sustentável (ODS), o cenário internacional torna-se palco de debates sobre a necessidade de preservação do meio ambiente para as futuras gerações e o direito ao desenvolvimento econômico e social.

Consolida-se, assim, o conceito de desenvolvimento sustentável, especialmente com a realização da Conferência das Nações Unidas sobre o Meio Ambiente e o Desenvolvimento (ECO 92) e, hodiernamente, com os ODS (GOMES; FERREIRA, 2018). Os aludidos objetivos, consoante documento oficial das Nações Unidas, são integrados e indivisíveis, equilibrando as três dimensões do desenvolvimento sustentável, a serem compreendidas de forma sistêmica: econômica, social e ambiental.

A seu tempo, compreendido como aquele capaz de suprir as necessidades da geração atual sem comprometer as futuras gerações, 0 desenvolvimento sustentável foi alçado à categoria de um dos mais relevantes princípios de Direito Ambiental na Constituição da República (FIORILLO, 2012).

A Carta da República, pois, diante dos novos ares da redemocratização, inspirada pela conjuntura internacional de proteção ao meio ambiente e pelos movimentos da sociedade civil organizada, traz em seu texto diretriz fundamental para a temática: 
"Art. 225. Todos têm o direito ao meio ambiente ecologicamente equilibrado, bem de uso comum do povo e essencial à sadia qualidade de vida, impondo-se ao Poder Público e à coletividade o dever de defendê-lo e preservá-lo para as presentes e futuras gerações." (BRASIL, 1988)

Assim, a Constituição Federal de 1988 confere ao meio ambiente um tratamento multidisciplinar e sistêmico, indo muito além da mera proteção formal aos bens naturais. Além do art. 225, acima mencionado, a CF/88 traz vários dispositivos intrinsicamente relacionados, tais como: defesa do meio ambiente como princípio da ordem econômica e financeira - art. 170, VI; política de desenvolvimento urbano - art. 182; função social da propriedade rural - art. 186, II; meio ambiente do trabalho - art. 200, VIII (BRASIL, 1988).

Delineia-se, portanto, uma "Política Constitucional Ambiental" (LEITE; VENÂNCIO, 2015). Verifica-se, dessa forma, a interdisciplinaridade com a qual os ordenamentos jurídicos internacional e nacional abordam o tema relativo ao meio ambiente. A complexidade da matéria, portanto, necessita da abordagem sistêmica tanto na compreensão dos problemas ambientais quanto na discussão das providências necessárias a serem implementadas.

A seu lado, nessa visão sistêmica, uma ferramenta intrinsecamente ligada à proteção e à preservação do meio ambiente vem a ser a Educação Ambiental. O ordenamento jurídico constitucional, notadamente o art. 205 da Constituição da República, pugna que a educação será promovida e incentivada com a colaboração da sociedade, inserindo entre os objetivos o pleno desenvolvimento da pessoa e seu preparo para o exercício da cidadania (BRASIL, 1988).

Cabe destacar ainda, que a Agenda 2030 para o Desenvolvimento Sustentável ${ }^{4}$ traz como objetivos, entre outros: educação de qualidade; cidades e comunidades sustentáveis; consumo e produção responsáveis.

Nessa toada, a Política Nacional do Meio Ambiente (Lei no 6.938/81, art. $2^{\circ}, \mathrm{X}$ ) alberga entre seus princípios a Educação Ambiental a todos os níveis de ensino, inclusive a educação da comunidade, objetivando capacitá-la para participação ativa na defesa do meio ambiente (BRASIL, 1981).

A Educação Ambiental, assim, desponta como potencial instrumento de diagnóstico, análise e reflexão acerca da problemática apresentada, considerando a multidisciplinaridade intrínseca à seara ambiental, notadamente entre as Ciências Sociais e Ambientais.

Não por outro motivo, a Lei de Diretrizes e Bases da Educação (LDB) Lei no 9.394/1996 - dispõe que o ensino fundamental obrigatório terá por objetivo a formação básica do cidadão, mediante a compreensão do ambiente natural e social, do sistema político, das artes e dos valores em que se

\footnotetext{
${ }^{4}$ Disponível em><https://nacoesunidas.org/pos2015/agenda2030/>. Acesso em: 20 jun. 2020.
} 
fundamenta a sociedade (art. 32, II da LDB). Igualmente, referida norma, ao tratar sobre a Base Nacional Comum Curricular (BNCC), impõe (art. $26 \mathrm{c} / \mathrm{c}$ art. 35-A, $\S 1^{\circ}$ da LDB) que a parte diversificada dos conteúdos, a ser complementada em cada sistema de ensino e em cada estabelecimento escolar, deverá ser articulada a partir do contexto histórico, econômico, social, ambiental e cultural (BRASIL, 1996).

Outrossim, por previsão legal expressa (art. 5ํㅡ da Lei ํㅡ 12.305/2010), a Política Nacional de Resíduos Sólidos integra a Política Nacional do Meio Ambiente e articula-se com a Política Nacional de Educação Ambiental em consonância com os princípios globais e antenada com a moderna visão sistêmica sobre o meio ambiente (BRASIL, 2010).

No que lhe concerne, a Política Nacional de Educação Ambiental, regulada pela Lei no 9.795/1999, prevê em seu art. 1ํ:

\begin{abstract}
"Entendem-se por Educação Ambiental os processos por meio dos quais o indivíduo e a coletividade constroem valores sociais, conhecimentos, habilidades, atitudes e competências voltadas para a conservação do meio ambiente, bem de uso comum do povo, essencial à sadia qualidade de vida e sua sustentabilidade " (BRASIL, 1999).
\end{abstract}

Por essa via, a Educação Ambiental é um tema transversal que precisa de atenção no meio educacional, uma vez que o trabalho pedagógico desenvolvido na escola deve proporcionar ações que instigam o educando para a complexidade crítica (UHMANN; VORPAGEL, 2018).

Ademais, a Política Nacional de Educação Ambiental (Lei oo 9.795/1999) vai além do aspecto meramente escolar, informando, em seu art. $3^{\circ}$, que todos têm direito à Educação Ambiental, cabendo à sua promoção ao Poder Público, às instituições educativas, aos órgãos integrantes do Sistema Nacional de Meio Ambiente (SISNAMA), aos meios de comunicação de massa, às empresas e à sociedade como um todo (BRASIL, 1999).

Além disso, congregando os elementos aqui dispostos, pode-se afirmar que um dos caminhos para se alcançar o desenvolvimento sustentável é justamente a implementação de políticas públicas ambientais dotadas de efetividade. E, para tanto, há que se perquirir o papel da Educação Ambiental como ator especial desse processo.

Diante de tal contexto, o corrente trabalho tem como objetivo analisar a viabilidade do uso da Educação Ambiental para e a execução da Política Nacional de Resíduos Sólidos em vigor no Brasil, a partir de experiências vivenciadas em políticas públicas ambientais específicas, no Brasil e no exterior, considerando a visão sistêmica inerente à temática do meio ambiente (aspectos sociais, ambientais, econômicos). 


\section{Metodologia}

A jornada metodológica traçada na execução do presente trabalho se realiza especificamente a partir da análise de três artigos: Delivery, impact and approach of household food waste reduction campaigns; Dead wood resources vary across different types of urban green spaces and depend on property prices; Critical factors for environmental regulation change management: Evidences from an extended producer responsibility case study.

Os referidos artigos foram escolhidos a partir da utilização da expressão "environmental education", na base de dados ScienceDirect. Posteriormente, fez-se a recuperação de 27 (vinte e sete) artigos publicados em 2020 (janeiro a abril) e, em seguida, houve o sorteio de 10\% (dez por cento) desses artigos para uma análise mais profunda, resultando nos 03 (três) textos acima apontados.

Posteriormente, busca-se traçar criticamente a rede sistêmica entre os temas abordados, mormente no que diz respeito à relação com a Educação Ambiental, traço subjacente primordial aos artigos acima mencionados. A abordagem sistêmica refere-se à interdisciplinaridade inerente às ciências ambientais, mormente em relação aos aspectos social, ambiental e econômico, uma vez que não podem ser analisados separadamente por conta de sua complexidade.

Por fim, a partir das experiências postas, busca-se perquirir a viabilidade e a relevância da Educação Ambiental para as políticas ambientais relativas aos resíduos sólidos no país e, consequentemente, ao desenvolvimento sustentável.

\section{Resultados e discussões}

\section{Delivery, impact and approach of household food waste reduction campaigns $^{5}$}

O primeiro artigo analisado versa sobre os impactos ambientais, econômicos e sociais referentes ao desperdício de alimentos. De início, fica evidente a abrangência dos temas nele propostos e o panorama sistêmico apontado.

Partindo da premissa de que grandes quantidades de alimentos são perdidas em todo o mundo desde o processo inicial de produção até a destinação dos resíduos sólidos, os autores abordam os programas destinados a enfrentar tal problemática, especialmente a mudança no comportamento do consumo das famílias, comparando os modelos adotados nos países desenvolvidos e em desenvolvimento.

${ }^{5}$ Disponível em: <https://doi.org/10.1016/j.jclepro.2019.118969>. 
Foram realizadas várias abordagens na coleta de dados (exemplificadamente: ambiental, econômica, sociais, políticas governamentais), sendo certo que a análise levou em consideração as famílias e os indivíduos em conformidade com a variedade cultural, os estágios de consumo e a diversidade social em diferentes países.

Nos países com grau menor de desenvolvimento, vários programas foram descontinuados por questões financeiras ou não tiveram todos os passos executados até o final. Em contrapartida, a maior parte dos países desenvolvidos tiveram os programas ultimados até a fase final de avaliação, nos quais foi possível inferir que a conscientização ambiental é bastante alta e a reciclagem faz parte da vida cotidiana, o que diminui, por consequência, o desperdício, evitando-se, também, o exaurimento dos aterros sanitários.

Uma das conclusões obtidas foi a de que programas educacionais podem ser considerados ferramentas baratas e eficientes de intervenção para o debate e o respectivo aumento de consciência sobre o desperdício de alimentos. Assim, envolver a comunidade em campanhas educacionais, de acordo com o texto, teria impacto mais significativo para a resolução do problema.

Demonstrou-se, portanto, que a Educação Ambiental, como fator de conscientização e mobilização social, perpassa transversalmente todos os projetos aplicados, servindo como catalizador para a efetividade das políticas públicas planejadas.

Em conclusão, melhorar a Educação Ambiental parece ser o método mais efetivo e economicamente viável para reduzir o desperdício alimentar, mormente se os projetos forem trabalhados de forma conjunta entre as autoridades públicas e a sociedade civil.

O texto sugere, ainda, a investigação mais detalhada sobre a conexão entre a questão religiosa e o desperdício de alimentos, alargando a margem para futuras conclusões e novos estudos, reforçando a abordagem sistêmica que o tema requer.

Em relação aos ODS, o assunto tratado no texto tem aproximação com pelo menos três objetivos presentes na Agenda 2030 da ONU: educação de qualidade; cidades e comunidades sustentáveis; consumo e produção responsáveis. 


\section{Dead wood resources vary across different types of urban green spaces and depend on property prices ${ }^{6}$}

Referido artigo apresenta, à primeira vista, viés mais ligado à temática ambiental natural, especificamente sobre o fato de que a madeira morta fornece importantes serviços ecossistêmicos, tendo efeito positivo na biodiversidade.

Procura, assim, nas diferentes áreas territoriais (espaços verdes urbanos, florestas remanescentes, jardins particulares, parques ...) da cidade de Cracóvia (Polônia), analisar os tipos de madeira morta (por exemplo: galhos, árvores em posição de vida) e a relação com a conservação da biodiversidade inerente a tais restos de vegetação.

Pelos dados obtidos, os autores apontam que certos tipos de madeira morta são importantes para a alimentação de vários microrganismos, sendo necessária a preservação de determinado resto de vegetação para a manutenção de tais seres e o equilíbrio do sistema. Portanto, ao tempo em que tais restos de plantas devem ser adequadamente mantidos nos espaços verdes urbanos, a remoção deve ficar restrita somente aos casos em que gerem algum tipo de perigo para a população.

Assim, de acordo com o conceito de crescimento urbano sustentável, as autoridades públicas devem incluir a conservação de biodiversidade nos respectivos planejamentos urbanos e estratégias de gestão.

Concluem, por fim, que a gestão dos recursos referentes aos restos de vegetação, combinada com a Educação Ambiental, é necessária para conservar a biodiversidade e os serviços ecossistêmicos. Nas campanhas de conscientização devem ser fornecidos subsídios apropriados (quadros ilustrativos, folhetos) explicando os objetivos e as razões para a preservação dos tipos específicos de restos de vegetação, a fim de aumentar o conhecimento e a aceitação social do tema.

Mais uma vez, observa-se a abrangência do objeto abordado, indo além da questão ambiental natural, percorrendo várias temáticas adjacentes (biológica, arquitetônica, urbanística, educacional, administrativa, gerencial), comprovando, novamente, a necessidade e a aplicabilidade do método sistêmico.

A seu turno, até pela abordagem estruturada pela visão de sistema, deixa em aberto a possibilidade de estudos futuros, especialmente se outros fatores, além da presença de tais restos de vegetação nas áreas urbanos, seriam necessários para sustentar a população de microrganismos ao longo do tempo.

${ }^{6}$ Disponível em: <https://doi.org/10.1016/j.landurbplan.2020.103747>. 
No que se refere aos ODS, podemos encontrar no artigo analisado dois objetivos presentes na Agenda 2030 da ONU: educação de qualidade; cidades e comunidades sustentáveis.

\section{Critical factors for environmental regulation change management: Evidences from an extended producer responsibility case study ${ }^{7}$}

$O$ texto em epígrafe diz respeito à situação em que a responsabilidade dos produtores (fabricantes, importadores) na destinação ambiental de um conjunto de produtos definidos é ampliada para além da fabricação, envolvendo especialmente a gestão de resíduos sólidos gerados após o final da vida útil. Como instrumento político, a responsabilidade ampliada, de acordo com o texto, tem, entre os objetivos, a transferência de parte do encargo da gestão de resíduos dos municípios aos produtores, bem como o incentivo à incorporação de questões ambientais no processo produtivo das empresas.

O estudo leva em consideração a experiência exitosa da Companhia Ambiental do Estado de São Paulo (CETESB), desde o momento em que a aludida entidade pública incorpora os princípios de regulação ambiental (descentralização, participação, flexibilidade, prevenção, multiinstrumentalidade, entre outros) na implementação da responsabilidade ampliada em SP.

O artigo relata a construção de um novo complexo de regulação ambiental, com a apropriação de novas responsabilidades e custos para determinadas empresas, o que culminou, de início, com certa resistência pelo setor privado atingido, sob alegação do surgimento de eventual desequilíbrio competitivo entre as empresas de São Paulo e as de outros Estados brasileiros.

A partir da narrativa apresentada, percebe-se ter sido imperiosa a superação dos modelos regulatórios ambientais tradicionais, com a necessidade de o poder público imprimir nova abordagem na relação com os atores econômicos e sociais, privilegiando a ocorrência de negociação entre as partes envolvidas. Assim, a incorporação dos princípios de regulação ambiental possibilitou a superação das dificuldades, a reabertura do diálogo e a realização de acordos entre a indústria e o governo.

O processo de mudança ocorreu, como apontado no artigo base, balizado por um novo modelo de governança, em que viceja o diálogo contínuo entre as empresas e o órgão ambiental, a realização de acordos setoriais, o planejamento de longo prazo, a fixação e a revisão de metas, bem como o investimento em Educação Ambiental como facilitador para o êxito das ações.

$\mathrm{Na}$ verdade, verifica-se que a implementação da responsabilidade ampliada passa pela contínua avaliação e superação dos problemas

\footnotetext{
7 Disponível em: <https://doi.org/10.1016/j.jclepro.2019.119013>.
}

revista brasileira educação ambiental 
percebidos ao longo da execução, o que permitiu a melhoria da infraestrutura de coleta e tratamento de resíduos, culminando com a criação, pelas próprias empresas, de organizações para aferir a responsabilidade do produtor. Houve, também, a expansão de participantes, com a adesão de municípios e varejistas. Por fim, houve a vinculação da observância dos princípios da responsabilidade ampliada ao processo de licenciamento ambiental.

Mais uma vez, com o aludido estudo de caso, evidencia-se a importância da visão sistêmica para a temática ambiental, na medida em que diversos fatores serviram como base para a execução do plano traçado (ambientais, jurídicos, gerenciais, econômicos, sociológicos, entre outros).

Ademais, novamente a Educação Ambiental desponta como fator indispensável para a consolidação de projetos na temática ambiental, no caso, como elemento intrínseco para o sucesso da política pública implementada.

Outro fator que merece destaque é a abertura que o texto oferece para novas pesquisas, sobretudo acerca da efetividade, no âmbito da experiencia paulista, da inserção dos princípios de regulação ambiental como requisito de licenciamento ambiental.

No pertinente aos ODS, o artigo comentado remete a pelo menos três objetivos da Agenda 2030 da ONU: educação de qualidade; cidades e comunidades sustentáveis; parcerias e meios de implementação.

\section{Da relevância da Educação Ambiental}

O meio ambiente equilibrado configura-se como um direito humano fundamental (BEZERRA; NETO, 2016). Ademais, a proteção ao meio ambiente constitui um "verdadeiro valor constitucional, vislumbrando-se um novo paradigma jurídico constitucional” (LEITE; VENÂNCIO, 2015: p. 125).

Nessa perspectiva, a Educação Ambiental pode ser vislumbrada como um dos garantidores para a efetividade das políticas públicas necessárias para o equilíbrio e a harmonização do meio ambiente; na hipótese particular deste artigo, para as políticas públicas relativas aos resíduos sólidos.

Com efeito, os três textos ora analisados tratam de aspectos inerentes aos resíduos sólidos (desperdício de alimentos, restos de madeira morta, ampliação da responsabilidade do produtor pelos detritos produzidos), demonstrando que a temática demanda a incorporação dos preceitos da Educação Ambiental como parte do planejamento das políticas públicas relativas ao meio ambiente.

Nesse contexto, as políticas públicas ambientais constituem os caminhos que levam ao desenvolvimento sustentável, sendo fundamental que se relacionem entre si e tenham, no conjunto, a Educação Ambiental como fator significativo para a efetividade dos objetivos por elas propostos. 
Em harmonia com esse debate, cabe destacar que o processo educativo se constitui como ferramenta essencial para que a sociedade seja capaz de realizar uma gestão sustentável no Século XXI (SANTOS; SOUZA, 2018).

Assim, baseando-se na análise dos textos ora abordados, traz-se à baila a Política Nacional de Resíduos Sólidos no Brasil. Esta faz parte de um conjunto mais amplo de iniciativas, consubstanciando, ao lado da drenagem urbana, do esgotamento sanitário e do abastecimento de água, o que concebemos como saneamento básico, nos termos da Lei ㄲo 11.445/2007 Política Nacional de Saneamento Básico (BRASIL, 2007).

Todos esses componentes relativos ao saneamento básico têm relação genérica e específica com a Educação Ambiental, devendo as políticas públicas gerais e setoriais serem por ela balizadas. Exemplifica-se: mesmo quando uma galeria de águas pluviais está dimensionada de maneira tecnicamente correta, sem Educação Ambiental a drenagem urbana pode não ser satisfatória caso a população não seja devidamente conscientizada sobre a importância de não obstruir a estrutura de passagem das águas. Da mesma forma, uma política de coleta seletiva pode não alcançar os resultados propostos se a comunidade não for informada adequadamente sobre a forma de separação residencial do lixo.

Por conseguinte, observa-se que as políticas públicas ambientais, entre elas a destinada aos resíduos sólidos, devem manter um diálogo sistêmico desde a fase de planejamento, a fim de que os objetivos se complementem e sejam harmônicos entre si, considerando todos os aspectos envolvidos. Igualmente, a Educação Ambiental, como fator estruturante e facilitador, deve ser um dos elos que permitam a efetividade de tais políticas.

Nessa esteira, além da normatização imposta pelo ordenamento jurídico legal e dos preceitos previstos na Agenda 2030 da ONU, as experiências concretas em diversas políticas públicas ambientais, nos âmbitos internacional e nacional, indicam de forma perceptível a imprescindibilidade dos princípios e objetivos da Educação Ambiental para o planejamento e a execução da Política Nacional de Resíduos Sólidos instituída pela Lei no 12.305/2010 (BRASIL, 2010).

\section{Conclusões}

Os três textos analisados possuem pontos similares que merecem ser destacados.

Sobressai-se em todos os artigos a abordagem sistêmica na discussão dos problemas ambientais visitados, demonstrando a imprescindibilidade da análise de todos os aspectos que envolvam as pesquisas sobre o meio ambiente, suas ramificações e os sistemas em que se inserem e se interconectam. 
Como produto da abordagem referenciada pelos textos estudados, avista-se, em cada um dos artigos, a possibilidade de novas pesquisas e aprofundamento de outras questões que surgem a partir dos resultados expostos, num círculo virtuoso de aprofundamento e descobertas.

Registre-se, como cediço, que, na perspectiva da Agenda 2030 da ONU, o traço comum revelado pelas experiências relatadas nos artigos analisados é justamente a educação de qualidade, nela inserida, obviamente, o viés ambiental.

Desse modo, a Educação Ambiental, à luz do enfoque sistêmico das variadas nuances ambientais, apresenta-se como fator estruturante e unificador das mais diversas políticas públicas ambientais, sendo, pois, imprescindível para demarcar o caminho agregador para a efetividade das propostas contidas no Plano Nacional de Resíduos Sólidos e, por conseguinte, para se alcançar o desenvolvimento sustentável.

\section{Referências}

BEZERRA, A. K. L.; NETO, J. M. A prática da Justiça Ambiental como mecanismo de efetividade do art. 225 da Constituição Federal. Direitos Culturais. Santo Ângelo, v. 11, n. 23: p. 37-52, jan./abr. 2016

BRASIL. Constituição da República Federativa do Brasil, de 5 de outubro de $1988 . \quad$ Disponível em: http://www.planalto.gov.br/ccivil 03/Constituicao/ConstituicaoCompilado.htm Acesso em: 20 jun. 2020.

BRASIL. Lei no 6.938, de 31 de agosto de 1981. Política Nacional do Meio Ambiente. Disponível em: http://www.planalto.gov.br/ccivil 03/LEIS/L6938.htm Acesso em: 20 jun. 2020.

BRASIL. Lei no 9.394, de 20 de dezembro de 1996. Lei de Diretrizes e Bases da Educação Nacional. Disponível em: http://www.planalto.gov.br/ccivil 03/leis//9394.htm Acesso em: 20 jun. 2020.

BRASIL. Lei no 9.795, de 27 de abril de 1999. Política Nacional de Educação Ambiental. Disponível em: http://www.planalto.gov.br/ccivil 03/leis/19795.htm Acesso em: 20 jun. 2020.

BRASIL. Lei $n^{\circ}$ 11.445, de 5 de janeiro de 2007. Política Nacional de Saneamento Básico. Disponível em: http://www.planalto.gov.br/ccivil 03/ ato2007-2010/2007/lei//11445.htm Acesso em: 20 jun. 2020.

BRASIL. Lei $n^{\circ}=12.305$, de 02 de agosto de 2010. Política Nacional de Resíduos Sólidos. Disponível em: http://www.planalto.gov.br/ccivil 03/ ato2007-2010/2010/lei//12305.htm Acesso em: 20 jun. 2020. 
FIORILLO, C. A. P. Curso de direito ambiental brasileiro. 13 ed. São Paulo, Saraiva, 2012.

FROHLICH, A.; CIACH, M. Dead wood resources vary across different types of urban green spaces and depend on property prices. Landscape and Urban Planning, Volume 197. Elsevier, 2020.

GOMES, M. F.; FERREIRA, L. J. Políticas públicas e os objetivos do desenvolvimento sustentável. Direito E Desenvolvimento. João Pessoa, Volume 09, 02: p. 155-178, dez. 2018.

LEITE, J. R. M.; VENÂNCIO, M. D. Hermenêutica jurídica ambiental para o século XXI: contornos e perspectivas. In: LEITE, J.R.M.; IGLECIAS, P.F. (Orgs). Direito Ambiental para o século XXI: novos contornos jurisprudenciais e na regulamentação dos resíduos sólidos/ São Paulo, Editora Revista dos Tribunais, p. 121-141, 2015.

RIBEIRO, F.M.; KRUGLIANSKAS, I. Critical factors for environmental regulation change management: Evidences from an extended producer responsibility case study. Journal of Cleaner Production. Volume 246. Elsevier, 2020.

SANTOS, T. M. M; SOUZA, B. I. de. Sociedade e Natureza: Interpretações, Reflexos na Educação Ambiental no Brasil e a Necessidade do Devir. Revista Brasileira de Educação Ambiental, v. 16, n. 04: p. 267-286, ago/2021.

THOMÉ, R. Manual de Direito Ambiental. 5 Ed., p. 42. Salvador: Juspodvim, 2015.

UHMANN, R. I. M.; VORPAGEL, F. S. Educação Ambiental em Foco no Ensino Básico. Pesquisa em Educação Ambiental. São Paulo, vol. 12, n. 02: p. 5368, 2018.

ZAMRI, G. B. et al. Delivery, impact and approach of household food waste reduction campaigns. Journal of Cleaner Production. Volume 246. Elsevier, 2020. 